\title{
BIOCHEMICAL STUDIES \\ ON 2-KETOGULONIC ACID METHYLESTER
}

\section{ON THE MECHANISM OF THE FORMATION OF VITAMIN C FROM 2-KETOGULONIC ACID METHYLESTER}

\author{
KEISUKE YASHIMA \\ Department of Medical Chemistry,* Kurume University School \\ of Medicine, Kurume-shi, Japan
}

The author bas already reported that 2-ketogulonic acid methylester (KGM) has an antiscorbutic action and, in the presence of the extract from plant and animal tissues, SH-compounds, barbituric acid derivatives etc., turn into a Vitamin C-like substance, which, in the author's opinion, is decided as ascorbic acid (AsA) (1-4).

If so, what sort of mechanism is at work for the formation of Vitamin $C$ from $\mathrm{KGM}$ ? Is the Vitamin $\mathrm{C}$ produced directly by enolisation and lactonisation from KGM which may take place? Or might it be assumed that Vitamin $\mathrm{C}$ is formed through some intermediary produced from KGM?

Sasamoto (5) has demonstrated that Vitamin $\mathrm{C}$ was produced from mannose via 2, 3-diketogulonic acid (DGA), while Suda (6) verified an increase in the reduction value of indophenol by incubating DGA with liver paste prepared from rabbits or white rats. Sasamoto and Beppu (7), on the other hand, proved this increased reduction value to be the real value of Vitamin $\mathrm{C}$ and demonstrated the possibility of the formation of AsA from DGA in vivo.

Having been interested in the mechanism for the formation of Vitamin $\mathrm{C}$ from KGM, the author has tricd the following experiments with a view to throwing some light on the problem.

\section{EXPERIMEN'TAL}

Preparation of Animal Tissue Extract.

Some content of fresh cow muscle mixed with a small amount of sea-sand was ground for about ten minutes, added with an approximately twenty fold content of water, ground again, and left standing for extraction for 30 minutes, and then centrifuged. The supernatant $(1: 20)$ obtained was used as the extract.

\footnotetext{
* Prof. : A. Ueta, M. D.
} 


\section{Experiment 1. The Temporal Progress of Vitamin C Production.}

The following experiment was made to observe the temporal change to be brought about in the presence of the extract in the amount of Vitamin C (V.C) produced from KGM.

To the phosphate buffer of $\mathrm{pH} 8.0$ (end concentration $M / 30$ ) were added the above mentioned extract (end concentration 1:100) and KGM (end concentration: $20 \mathrm{mg} \%$ ); the solution was kept at $37 \mathrm{C}$ all the time and then the amount of $\mathrm{V} . \mathrm{C}$ was determined every hour by the phospho-18-tungstic acid method (8). The result of this experiment is presented in Fig. 1.

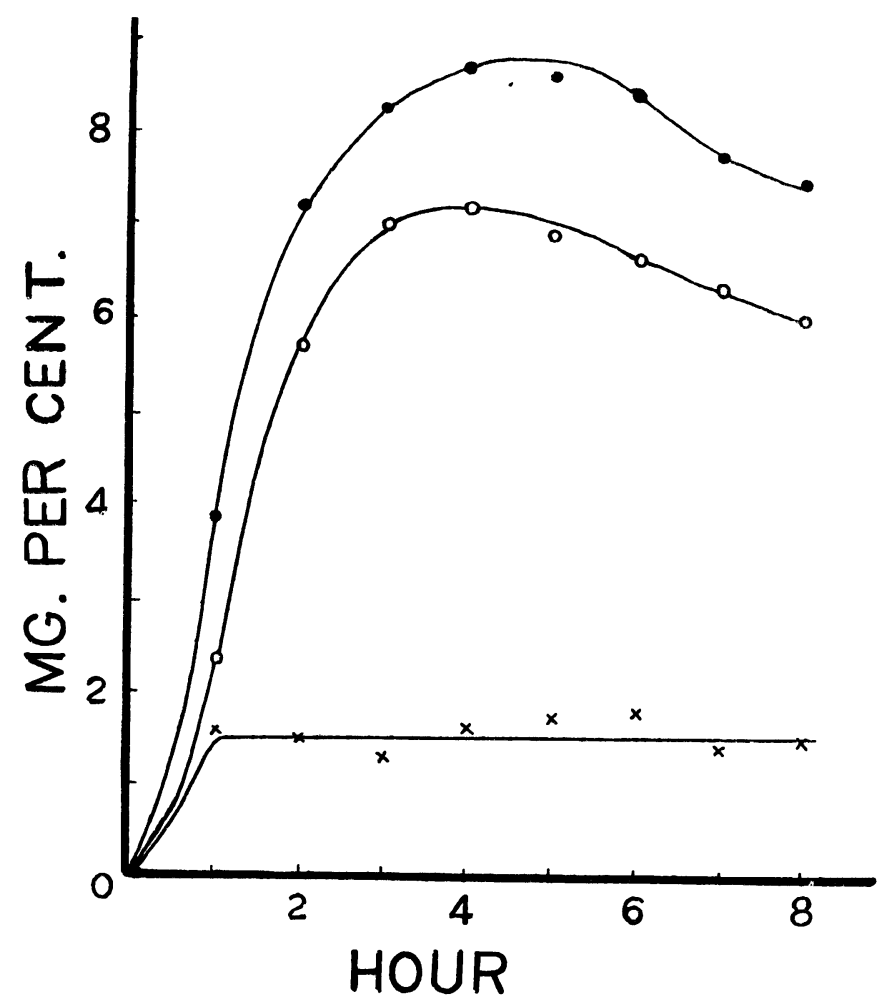

Fig. 1. The temporal progress of Vitamin $\mathrm{C}$ production.

To the phosphate buffer of $\mathrm{pH} 8.0$ were added the above mentioned extract and $\mathrm{KGM}$; the solution was kept at $37^{\circ} \mathrm{C}$ all the time and then the amount of V.C determined every hour by the phospho-18-tungstic acid method. End concentration: buffer $(M / 30)$, extract $(1: 100)$, KGM (20 $\mathrm{mg} \%$ ).

○, total V.C ; O, AsA; $\times$, DAA. 
The unit of these experimental values was expressed as $\mathrm{mg} \%$, and these reduction values were regarded from the result of the cross experiment carried out by the enzyme method(4), as those of the real content of V.C.

The reduced form of V.C (AsA) apparently increased in parallel with the time passed, reaching maximam in 4 hours, began to decrease gradually. Similarly, the total amount of V.C (AsA + DAA) also continued to increase gradually for 4 hours and thereafter decreased. Conversely, the oxidized form of V.C (dehydroascorbic acid, DAA) increased rapidly in about an hour and went on increasing persistently thereafter.

Experiment 2. Demonstration of the Existence of DGA.

As the existence of DGA was suspected under the above mentioned condition of reaction, the amount of DGA and total V.C was measured by Roe's 2, 4-dinitro-

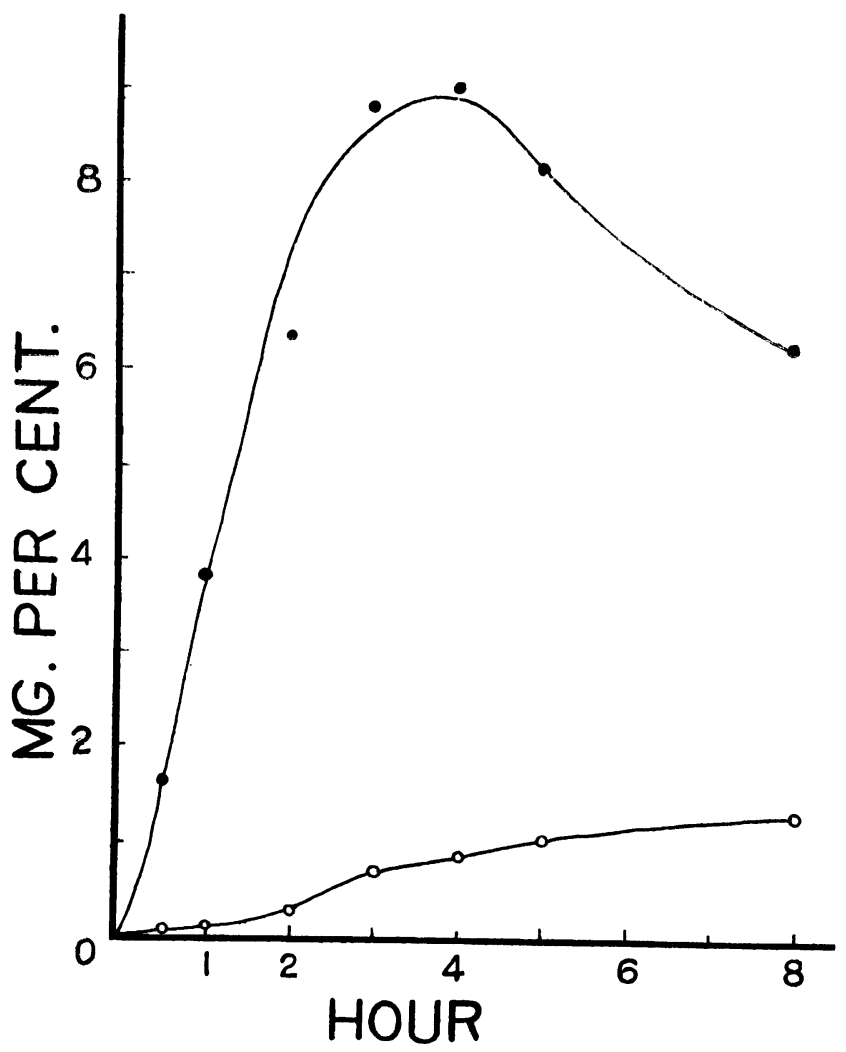

Fig. 2. Demonstration of the existence of DGA.

The amount of DGA and total V.C measured by method of Roe. , total V. C; O, DGA. The other experimental conditions are same as Fig. 1. 
phenylhydrazine method (9) under the same condition as Experiment 1. As shown in Fig. 2, the formation of DGA was proved, and its amount was also simultaneously shown to increase more and more with the lapse of time. As in the previous experiment, the total amount of V.C went on increasing for 3 to 4 hours and then began to decreases gradually.

Experiment 3. The Result of the Addition of AsA at the Begining.

The following experiment was made to see whether DGA would be produced or not from AsA added previously under the same condition as that for Experiments 1 and 2 .

(Control 1) $5.0 \mathrm{ml}$ of phosphate buffer in $\mathrm{pH} 8.0,1.0 \mathrm{ml}$ of extract and $2 \mathrm{mg}$ of KGM were dissolved in water so as to make up a total of $10 \mathrm{ml}$.

(Main experiment) $5.0 \mathrm{ml}$ of buffer, $1.0 \mathrm{ml}$ of extract and $1.0 \mathrm{ml}$ of $80 \mathrm{mg} \%$ AsA are dissolved in water so as to make up a total of $10 \mathrm{ml}$.

(Control 2) $5.0 \mathrm{ml}$ of buffer, $1.0 \mathrm{ml}$ of extract were dissolved in water so as to make up a total volume of $10 \mathrm{ml}$.

After the reactions had been going on for 4 hours in each solution kept at $37^{\circ} \mathrm{C}$, the amount of DGA and total V.C were measured. The results are presented in Table 1.

Table 1.

The result of the addition of As at the begining.

\begin{tabular}{l|c|c}
\hline \multicolumn{1}{c|}{ Condition } & Amount of total V.C & Amount of DGA \\
\hline $\begin{array}{l}\text { Main experiment } \\
\text { (Addition of AsA) }\end{array}$ & 5.76 & mg. per cent. \\
$\begin{array}{l}\text { Control 1 } \\
\text { (Addition of KGM) }\end{array}$ & 8.17 & 0.84 \\
Control 2 & $0(<0.03)$ & 0.78 \\
\hline
\end{tabular}

After the reactions had been going on for 4 hours in each solution kept at $37^{\circ} \mathrm{C}$, the amount of DGA and total V.C were measured by method of Roe.

AsA was oxidized to form DGA in the author's main experiment which was carried out by adding AsA from the outset under the same condition as that of control 1.

Experiment 4. Formation or Non-Formation of DGA in the Absence of $\mathrm{O}_{2}$.

As has been described above, it was confirmed that the formation of V.C from $\mathrm{KGM}$ is possible in the absence of $\mathrm{O}_{2}$. It was next investigated whether DGA was formed or not when the reaction in caused is a stream of $\mathrm{H}_{2}$ by 
which the V.C produced might be prevented as far as possible from getting oxidized.

$5.0 \mathrm{ml}$ of phosphate buffer, $1.0 \mathrm{ml}$ of $0.2 \% \mathrm{KGM}$ and $3.0 \mathrm{ml}$ of water were poured into the main room of Fujita's modification of Tunberg's tube (10), and $1.0 \mathrm{ml}$ of the extract into the side room. After this content was saturated with $\mathrm{H}_{2}$ (refined by pyrogallol) or air, the stop cock was shut up. After the two contents were mixed, and left standing on a water-bath for 3 hours at $37^{\circ} \mathrm{C}$, the total amount of V.C and DGA was determined. The control was, on the other hand, not saturated with gas. The results are indicated in Table 2.

Table 2.

Formation or non-formation of DGA in the absence of $\mathrm{O}_{2}$.

\begin{tabular}{|c|c|c|c|}
\hline & Condition & Amount of total V. C & Amount of DGA \\
\hline \multicolumn{2}{|c|}{$\begin{array}{l}\text { Immediately after } \\
\text { reagents were mixed }\end{array}$} & $\begin{array}{c}\text { mg. per cent. } \\
0(<0.03)\end{array}$ & $\begin{array}{c}\text { mg. per cent } \\
0(<0.03)\end{array}$ \\
\hline \multirow{3}{*}{ 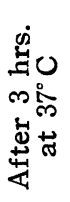 } & $\begin{array}{l}\text { Saturated } \\
\text { with } \mathrm{H}_{2}\end{array}$ & 9.57 & $0(<0.03)$ \\
\hline & $\begin{array}{l}\text { Saturated } \\
\text { with air }\end{array}$ & 6.45 & 1.09 \\
\hline & $\begin{array}{l}\text { Not streamed } \\
\text { gas }\end{array}$ & 7.32 & 0.94 \\
\hline
\end{tabular}

End concentration: Buffer $(M / 30), \mathrm{KGM}(20 \mathrm{mg} \%)$, Extract $(1: 100)$. Determination : Method of Roe.

The existences of total V.C and DGA were observed in the presence of $\mathrm{O}_{2}$. It was thus seen that there could be no production of DGA in this experiment though V.C was producible without $\mathrm{O}_{2}$.

Experiment 5. Formation or no Formation of DGA from AsA added at the Start in the Abscnce of $O_{2}$.

The following experiments were undertaken to determine whether DGA is yielded or not from AsA added at the start in a stream of $\mathrm{H}_{2}$.

(Main experiment) $5.0 \mathrm{ml}$ of buffer solution, $1.0 \mathrm{ml}$ of the extract and $1.0 \mathrm{ml}$ of $100 \mathrm{mg} \%$ AsA were dissolved in water so as to make up a total of $10 \mathrm{ml}$.

(Control) $1.0 \mathrm{ml}$ of $0.2 \% \mathrm{KGM}$ was added instead of $1.0 \mathrm{ml}$ of AsA added in the main experiment.

These two kinds of solution were saturated with $\mathrm{H}_{2}$ in Tunberg's tube (10) as already described in Experiment 4. When mixed up, each solution was left standing in a water-bath of $37^{\circ} \mathrm{C}$ for 3 hours, and the total amount of V.C and DGA was estimated by the method of Roe. The results are shown in Table 3 . 
Table 3.

Formation or no formation of DGA from AsA added at the start in the absence of $\mathrm{O}_{2}$.

\begin{tabular}{c|c|c}
\hline Condition & Amount of total V.C & Amount of DGA \\
\hline mg. per cent. & mg. per cent. \\
& 9.09 & $0(<0.03)$ \\
& & $0(<0.03)$ \\
\hline
\end{tabular}

End concentration : KGM (20 mg \%), AsA (10 mg\%).

The other experimental conditions are same as Table 2.

In the control, AsA and DAA were formed, but not DGA, as already mentioned. In the main experiment also in which AsA was added at the begining, the total amount of V.C was found unoxidized, and V.C added at the start was redetected and on formation of DGA was observed at all.

\section{DISCUSSION}

It was proved experimentally that the amount of V.C decreased in a certain period of time not only in AsA, but also in the total V.C (AsA +DAA). This result seems to indicate that AsA produced by decomposition is converted into DAA and further into some substance unreduciable by $\mathrm{H}_{2} \mathrm{~S}$.

Experiment (Exp.) 2, carried out on the basis of this idea resulted in the expected confirmation of the existence of DGA, the secondary is a decomposition product of DAA.

It is well known that, in a substance like DAA, the lactone ring contained, a part of its constitutional fomula at $\mathrm{C}_{I I}$ and $\mathrm{C}_{\mathrm{II}}$ positions shown as $-\stackrel{\|}{\mathrm{C}}-\stackrel{\mathrm{C}}{\mathrm{C}}-$, is easily broken down by alkalinization as in DAA. According to Herbert (11) and Borsook (12), DAA turnes into DGA quickly when left alkaline at $\mathrm{pH}$ 9, slowly when left slightly acidic or neutral, by breaking down its lactone ring. In the author's experiments also, which were performed in a medium at $\mathrm{pH} 8$, it was easily conceivable that DAA may turn into DGA which is irreversible to AsA by breaking
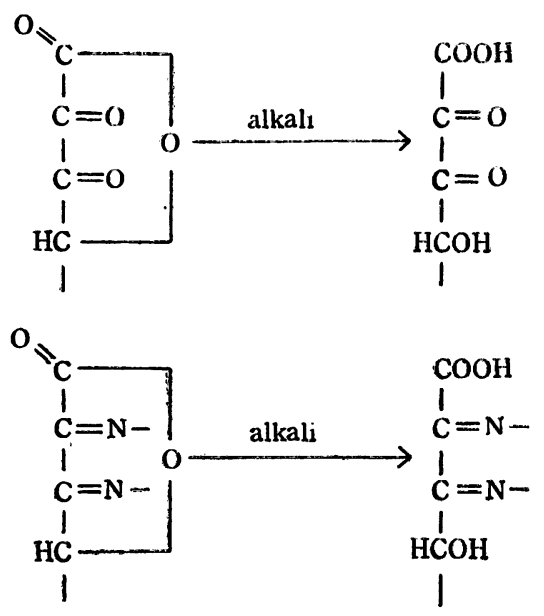
down the lactone ring, and by $\mathrm{H}_{2} \mathrm{~S}$. 
As stated by Sasamoto (5), however, DGA may be regarded as an intermediary product during the formation of AsA, so that it is not yet evident whether DGA demonstrated in Exp. 2 is a substance produced in the course of the oxidation and decomposition of AsA or an intermediary product during the formation of AsA.

Exp. 3 was undertaken to investigate the problem if DGA was formed from AsA when the latter is added in the condition described above at the start as in the case of Exp. 2. The result proved that DGA was produced from AsA added at the start, while AsA was oxidized and decomposed to be converted to DGA in the author's experimental condition. This fact indicates that DGA produced in Exp. 2 is more likely to be produced by oxidizing AsA, which is the product from KGM.

In Exp. 4, however, it was discovered, contrary to expectation, that DGA was not formed when KGM was left to react in the absence of $\mathrm{O}_{2}$, and that while AsA was formed from KGM in the absence of $\mathrm{O}_{2}$, DGA was not formed anew. This fact, together with the above mentioned opinion, indicates, to the author's thinking, that AsA is formed from KGM not through DGA, but directly. The author's presumption is likely to be verified by the result of Exp. 5 in which DGA is not produced in the reaction system free from $\mathrm{O}_{2}$ when AsA is added at the start. Moreover, the result of Exp. 2, in which the amount of produced DGA went on rising with the lapse of time, seems to make it probable that DGA is not an intermediary product in the formation of AsA.

Sasamoto demonstrated that the formation of V.C from mannose is performed via DGA, and Mishima (13) suggested that 2-ketogulonic acid might be an intermediary substance produced during the formation of V.C in the eye lens. It seems unsettled which of the two substances, DGA or 2-ketogulonic acid, is produced earlier as an intermediary substances in the formation of V.C.

The author has been in support of the hypothesis of Micheel $e t$ al. that during the formation of V.C from 2-ketogulonic acid, enolisation takes place and the cis-form of these enol-forms form a lactone ring to yield AsA. 
2-keto-L-gulonic acid

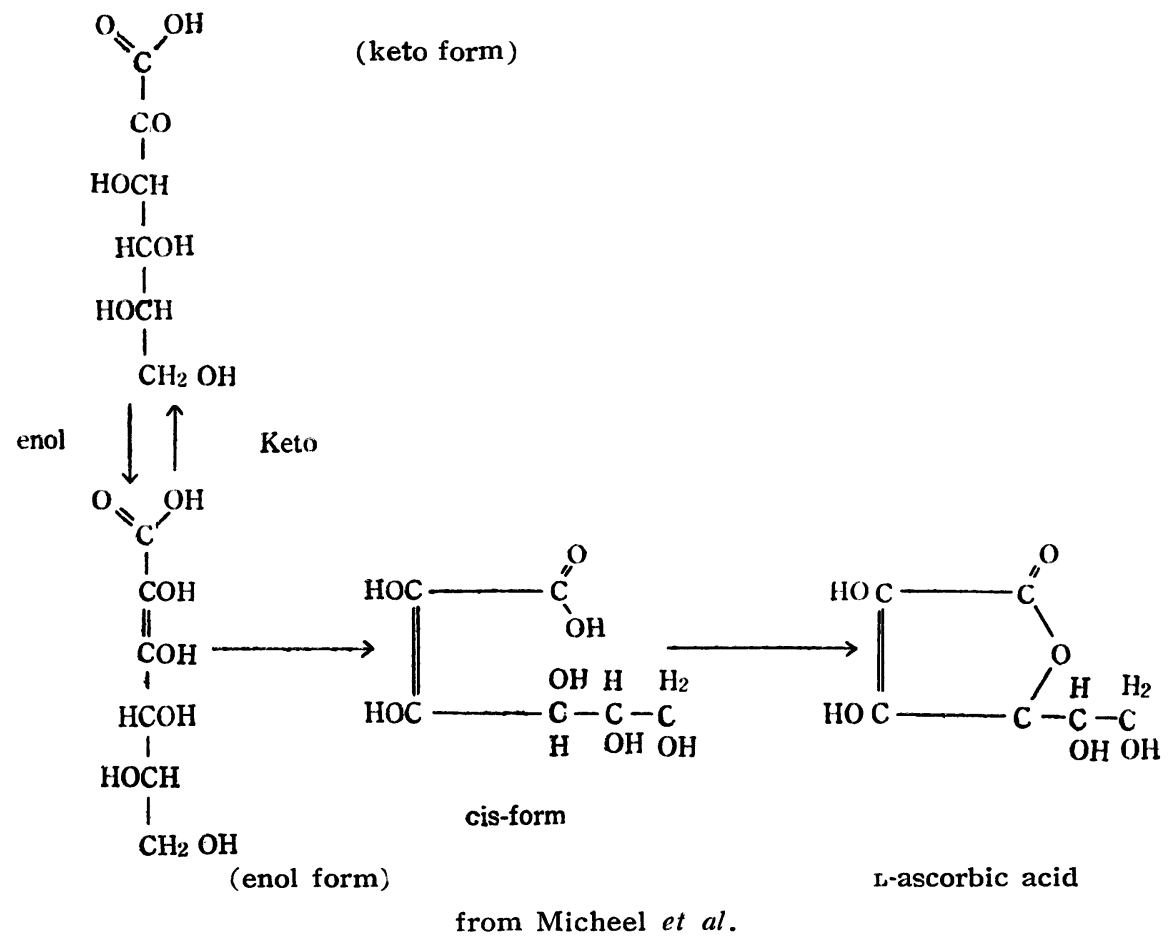

The author thinks it is possible to prove the validity of the hypothesis experimentally to some extent.

The fact that DGA is no intermediary substance produced during the formation of V.C, makes it conceivable that the amount of DAA formed in Exp. 1 was practically constant (Fig. 1) because the reaction rate was practically the same for AsA $\rightarrow$ DAA and for DAA $\rightarrow$ DGA.

\section{SUMMARY}

The mechanism for the formation of V.C by KGM, in the presence of an extract prepared from cow's muscle, was examined.

1. The amount of V.C produced was measured at regular intervals of time. The total V.C was seen to drop after a certain period of time.

2. The cause of the decrease is that AsA is oxidized to be decomposed into DAA and then shifted to DGA or other substances.

3. The formation of V.C from KGM is performed directly, and not through DGA. 
The course of this reaction and that of the decomposition of V.C may be presumed as follows.

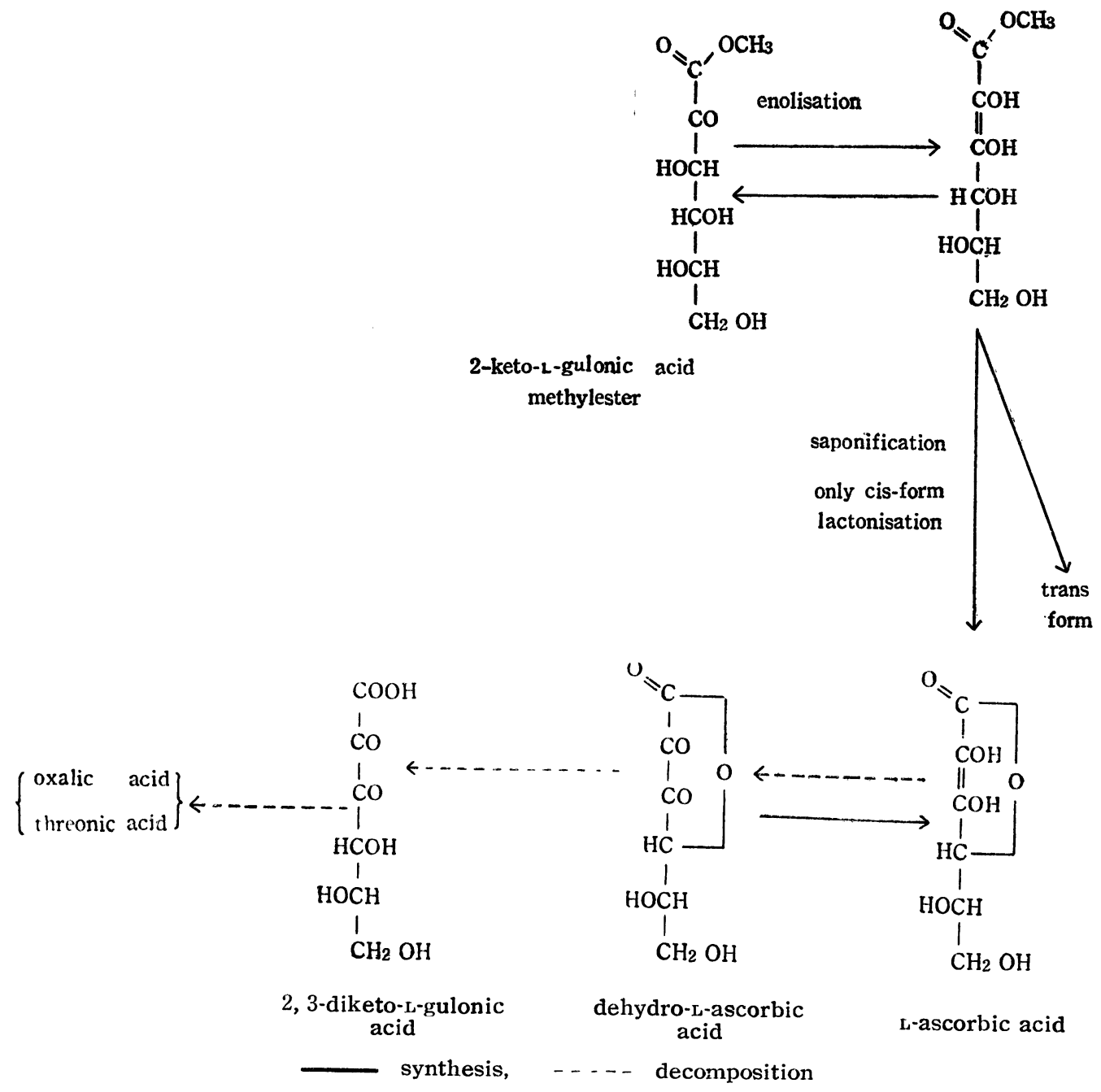

The author wishes to express his thanks to Prof. Ueta and Dr. Onodera for their revision of this paper.

This research was subsidized by a grant given to Dr. Onodera, from the Fundamental Scientific Research Grants, Ministry of Education. 


\section{REFERENCES}

1-4. Yashima, K.: Biochemical studies on 2-ketogulonic acid methylester (I-IV), Vitamins, Vol. 6, 540-549, 1953; Vol. 7, 139-145, 1954.

5. Sasamoto, T.: On the metabolism of Vitamin C (V), Vitamins, Vol. 4, 429-430, 1951.

6. SudA, I.: Studies on ascorbic acid oxidized by ascorbic acid oxidase. The Journal of Osaka Medical Society, Vol. 40, 518-528, 1941.

7. Sasamoto, T. and Beppu, K.: On the metabolism of Vitamin C (III), Vitamins, Vol. 4, 425-426, 1951.

8. Fujita, A.: The chemical determination of vitamins, The First Edition, 176-185, Seibundô-Shinkôsha, Tokyo, 1948.

9. Roe, J. H. and Kuether, C. A.: The determination of ascorbic acid in whole blood and urine through the 2, 4-dinitrophenylhydrazine derivative of dehydroascorbic acid. J. Biol. Chem., Vol. 147, 399-407, 1943.

Roe, J. H., Mirls, M. B., et al.: The determination of diketo-L-gulonic acid, dehydro$\mathrm{L}$-ascorbic acid and $\mathrm{L}$-ascorbic acid in the same time tissue extract by the 2, 4dinitrophenylhydrazine method. J. Biol. Chem., Vol. 174, 201-208, 1948.

10. Fujita, A.: The chemical determination of vitamins, The First Edition, 164, SeibundoShinkôsha, Tokyo, 1948.

11. Herbert, R. W., Hirst, E. L., et al.: The constitution of ascorbic acid. J. Chem. Soc., 1270-1290, 1933-II.

12. Borsook, H., Davenport, H. W., et al.: The oxidation of ascorbic acid and its reduction in vitro and in vivo., J. Biol. Chem., Vol. 117, 237-279, 1937.

13. Mishima, K.: On the metabolism of Vitamin C in lens, Acta Societatis Ophthalmologicae Japonicae, Vol. 55, 1004-1010, 1951. 